\title{
REACH AND PALMAR GRASP IN TETRAPLEGICS WITH NEUROMUSCULAR ELECTRICAL STIMULATION
}

\author{
ALCANCE EPREENSÃO PALMAR EM TETRAPLÉGICOS COM ESTIMULAÇÃO ELÉTRICA NEUROMUSCULAR
}

ALCANCE Y PRENSIÓN PALMAREN TETRAPLÉJICOS CON ESTIMULACIÓN ELÉCTRICA NEUROMUSCULAR

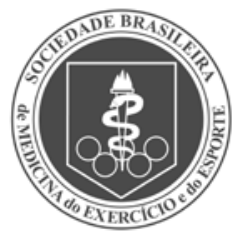

Original Article ARTIGo ORIGINAL Artículo Original
Enio Walker Azevedo Cacho' (Physiotherapist)

Roberta de Oliveira Cacho (Physiotherapist)

Rodrigo Lício Ortolan² (Electrical Engineer)

Núbia Maria Freire Vieira Lima' (Physiotherapist)

Edson Meneses da Silva Filho (Physiotherapist)

Alberto Cliquet Jr, $\mathrm{r}^{3,4}$

(Electronics Engineer)

1. Universidade Federal do Rio Grande do Norte, Faculdade de Ciências de Saúde do Trairi, Santa Cruz, RN, Brazil. 2. Instituto Federal de Educação, Poços de Caldas, MG, Brazil. 3. Universidade Estadual de Campinas, Faculdade de Ciências Médicas, Campinas, SP, Brazil. 4. Universidade de São Paulo, São Carlos, SP, Brazil.

\section{Correspondence:}

Edson Meneses da Silva Filho. FACISA/UFRN. Rua Vila Trairi, s/n, Centro, Santa Cruz, RN, Brazil. 59200-000.

meneses.edson@yahoo.com.br

\begin{abstract}
Objective:To evaluate the movement strategies of quadriplegics, assisted by neuromuscular electrical stimulation, on reach and palmar grasp using objects of different weights. Methods: It was a prospective clinical trial. Four chronic quadriplegics (C5-C6), with injuries of traumatic origin, were recruited and all of them had their reach and palmar grasp movement captured by four infrared cameras and six retro-reflective markers attached to the trunk and right arm, assisted or not by neuromuscular electrical stimulation to the triceps, extensor carpi radialis longus, extensor digitorum communis, flexor digitorum superficialis, opponens pollicis and lumbricals. It was measured by a Neurological and Functional Classification of Spinal Cord Injuries of the American Spinal Injury Association, Functional Independence Measure and kinematic variables. Results: The patients were able to reach and execute palmar grasp in all cylinders using the stimulation sequences assisted by neuromuscular electrical stimulation. The quadriplegics produced lower peak velocity, a shorter time of movement and reduction in movement segmentation, when assisted by neuromuscular electrical stimulation. Conclusion: This study showed that reach and palmar grasp movement assisted by neuromuscular electrical stimulation was able to produce motor patterns more similar to healthy subjects. Level of evidenceIV; Case series.
\end{abstract}

Keywords: Spinal cord injury; Tetraplegia; Rehabilitation.

\section{RESUMO}

Objetivo: Avaliar as estratégias de movimento de quadriplégicos com o auxilio de estimulação elétrica neuromuscular sobre o alcance e a preensão palmar com objetos de diferentes pesos. Métodos: Estudo clínico prospectivo. Quatro quadriplégicos crônicos (C5-C6) com lesões de origem traumática foram recrutados e todos tiveram o alcancee movimento de preensão palmar capturado por quatro câmeras infravermelho e seis marcadores retrorreflexivos fixados no tronco e braço direito, assistidos ou não por estimulação neuromuscular do tríceps, extensor radial longo do carpo, extensor dos dedos, flexor superficial dos dedos, oponente do polegar e músculos lumbricais. A medida foi feita com base na Classificação Neurológica e Funcional de Lesões Medulares da American Spinal Injury Association, na Medida de Independência Funcional eem variáveis cinemáticas. Resultados: Os pacientes foram capazes de alcançar e realizar preensão palmar em todos os cilindros utilizando as sequências de estimulação auxiliadas por estimulação elétrica neuromuscular. Os quadriplégicos produziram menor velocidade de pico, menor tempo de movimento e redução na segmentação do movimento, quando foram auxiliados pela estimulação elétrica neuromuscular. Conclusão: Esteestudo mostrou que o alcancee o movimento de preensão palmar assistidos por estimulação elétrica neuromuscular foi capaz de produzir padrões motores mais semelhantes aos dos indivíduos saudáveis. Nivel de evidência IV; Série de casos.

Descritores: Traumatismos da medula espinal; Tetraplegia; Reabilitação.

\section{RESUMEN}

Objetivo: Evaluar las estrategias de movimiento de cuadripléjicos, con el auxilio de estimulación eléctrica neuromuscular sobre el alcancey la prensión palmar con objetos de diferentes pesos. Métodos: Estudio clínico prospectivo. Fueron reclutados cuatro cuadripléjicos crónicos (C5-C6) con lesiones de origen traumático y todos ellos tuvieron su alcance y movimiento de prensión palmar capturado por cuatro cámaras infrarrojas y seis marcadores retrorreflexivos fijados al tronco y al brazo derecho, asistidos o no por estimulación neuromuscular del tríceps, extensor radial largo del carpo, extensor de los dedos, flexor superficial de los dedos, oponente del pulgary músculos lumbricales. La medición fue hecha con base en la Clasificación Neurológica y Funcional de Lesiones Medulares de la American Spinal Injury Association, en la Medida de Independencia Funcional y en variables cinemáticas. Resultados: Los pacientes fueron capaces de alcanzar y realizar prensión palmar en todos los cilindros utilizando las secuencias de estimulación auxiliadas por estimulación eléctrica neuromuscular. Los cuadripléjicos produjeron menor velocidad de pico, menor tiempo de movimiento y reducción en la segmentación del movimiento, cuando fueron auxiliados por la estimulación eléctrica neuromuscular. Conclusión: El presente estudio mostró que el alcance y el movimiento de prensión palmar asistidos por estimulación eléctrica neuromuscular fue capaz de producir patrones motores más similares a los individuos saludables. Nivel de evidencia IV; Serie de casos.

Descriptores: Traumatismos de la Médula Espinal; Cuadriplejía; Rehabilitación. 


\section{INTRODUCTION}

In the cervical spinal cord injuries, impaired arm and hand function is straight connected to the loss of functional independence level in quadriplegics ${ }^{1}$ and recovery of Upper Limb (UL) movements is essential for the rehabilitation of these individuals. Several therapeutic interventions are used, in an attempt to improve the sensory and motor deficits, such as tendons transfers, orthosis and Neuromuscular Electrical Stimulation (NMES) 1,2.

The NMES has been used in the rehabilitation of individuals with spinal cord injury since the $X X^{\text {th }}$ century. The motor function recovery of upper extremities by NMES remains less elaborated than the lower extremity, mainly due to the higher functional complexity of the UL movements. Advances in computer technology in association with better biomechanical understanding have allowed to overcome some difficulties. Computer systems of multi-channel NMES can simultaneously control many muscles of the hand and arm with large degrees of freedom ${ }^{3}$.

Several researches have evaluated the use of NMES as an effective method to recover the UL movements. However, the instruments used to measure the action of NMES in quadriplegics' reach and grasp movements are mostly medical or functional and often not specific to the UL assessment ${ }^{4,5}$.

Kinematics evaluations of the upper extremity have been developed ${ }^{6}$ and used in the analysis of movement strategies ${ }^{7,8}$. Some kinematic variables describe characteristics of movement patterns and can provide quantitative data for a better understanding of the motor control. Thus, in order to develop and evaluate therapeutic approaches by quantitative measures, the aim of the study was to evaluate the movement strategies of reach and palmar grasp of quadriplegic subjects using different objects, assisted by NMES.

\section{METHODS}

Four chronic quadriplegics, all male, (mean time of injury 9.7 years, Standard Deviation (SD) 6.42 years, mean age 31.0 years, SD 6.49 years) performed reach and palmar grasp movements with and without assistance of the Neuromuscular Electrical Stimulation (NMES) (Table 1). The quadriplegics were recruited from Biomechanics and Rehabilitation Laboratory at University of Campinas (Unicamp) and all of them signed the consent form, previously approved by the Local Ethics Research Committee (\# 595/2005).

Prior to the kinematic captures, all patients selected for the study received 20 sessions of NMES therapy, twice a week, with 10 weeks of duration. The strengthening sessions plus training, prior to the kinematic study of movement strategies, has the objective to condition the paretic or plegic muscles to the functional activity.

The twenty sessions were divided in 10 strengthening sessions and 10 sessions of functional training of reaching and grasping assisted by electrical stimulation (Figure 1). The strengthening sessions consisted of 20 minutes of electrical stimulation on muscles triceps, extensor carpi radialis longus, extensor digitorum communis, lumbricalis, flexor digitorum superficialis and opponens pollicis.

The functional training sessions were performed through reach and palmar grasp movements with NMES using cylindrical and conical objects

Table 1. Quadriplegics clinical data.

\begin{tabular}{c|c|c|c|c}
\hline Quadriplegics & $\begin{array}{c}\text { Neurological } \\
\text { level/ASIA }\end{array}$ & $\begin{array}{c}\text { Motor level } \\
\text { right }\end{array}$ & $\begin{array}{c}\text { Motor index } \\
\text { right }\end{array}$ & $\begin{array}{c}\text { FIM Motor } \\
\text { score }\end{array}$ \\
\hline 1 & C5/A & C6 & 11 & 32 \\
\hline 2 & C6/A & C7 & 14 & 25 \\
\hline 3 & C6/A & C6 & 10 & 34 \\
\hline 4 & C5/B & C5 & 6 & 20 \\
\hline Mean/sd & & & $10.2 / 3.3$ & $27.7 / 6.4$ \\
\hline
\end{tabular}

ASIA, American Spinal Injury Association; A, complete lesion; B, incomplete lesion; FIM, Functional independence measure; sd, standard deviation. of different weights (30-minute-session). The NMES, brand EarthPulse ${ }^{\mathrm{TM}}$ and model E-Stim, was used to facilitate movements of reaching (triceps muscle), opening (extensor carpi radialis longus and extensor digitorum communis muscle), positioning (extensor carpi radialis longus, flexor digitorum superficialis and lumbricalis muscles), palmar grasp (extensor carpi radialis longus, flexor digitorum superficialis, opponens pollicis muscles) and releasing (extensor carpi radialis longus and extensor digitorum communis muscles) (Figure 2). As the temporal organization varied among quadriplegics, some of them required more time to some stages of the sequence.

For NMES, the eight-channel stimulator, controlled by a microcomputer was used with pulse frequency, $25 \mathrm{~Hz}$; pulse duration, 300 Hseconds; on/off duration 2/2sec; maximum pulse width fixed at $250 \mu \mathrm{A}$, and the amplitude was individually adjusted to achieve the excitability threshold for each muscle. The amplitude was adjusted throughout the training, in order to produce muscle contraction. These parameters were used in all of therapies and in the kinematic assessment. The stimulation was applied with self-adhesive surface electrodes taped to the skin (Figure 3). Two sequences of stimulation were used: one for the quadriplegics "1", "3" and "4", and another one for the subject" 2 ", without any control in closed loop.

The four participants selected in the study underwent conventional physiotherapy weekly during the search, including strengthening activities (without NMES), passive and active stretching and functional activities training of daily living.

For kinematic captures, the participants performed reach and palmar grasp movements with the dominant arm (right), assisted and not assisted by NMES. The subjects had no restriction for trunk anterior shifting, but for safety reasons they were kept seated in their own daily use wheelchair (the one they were more adapted to) and the non-dominant arm

\begin{tabular}{|c|c|c|c|}
\hline $\begin{array}{l}\text { Admission } \\
\text { in the study }\end{array}$ & $\begin{array}{l}\text { First intervention: } \\
10 \text { strengthening } \\
\text { sessions }\end{array}$ & $\begin{array}{l}\text { Second intervention: } \\
10 \text { functional training } \\
\text { sessions }\end{array}$ & $\begin{array}{l}\text { Clinical and } \\
\text { Kinematic } \\
\text { assessments }\end{array}$ \\
\hline
\end{tabular}

Figure 1. Diagram of study design.

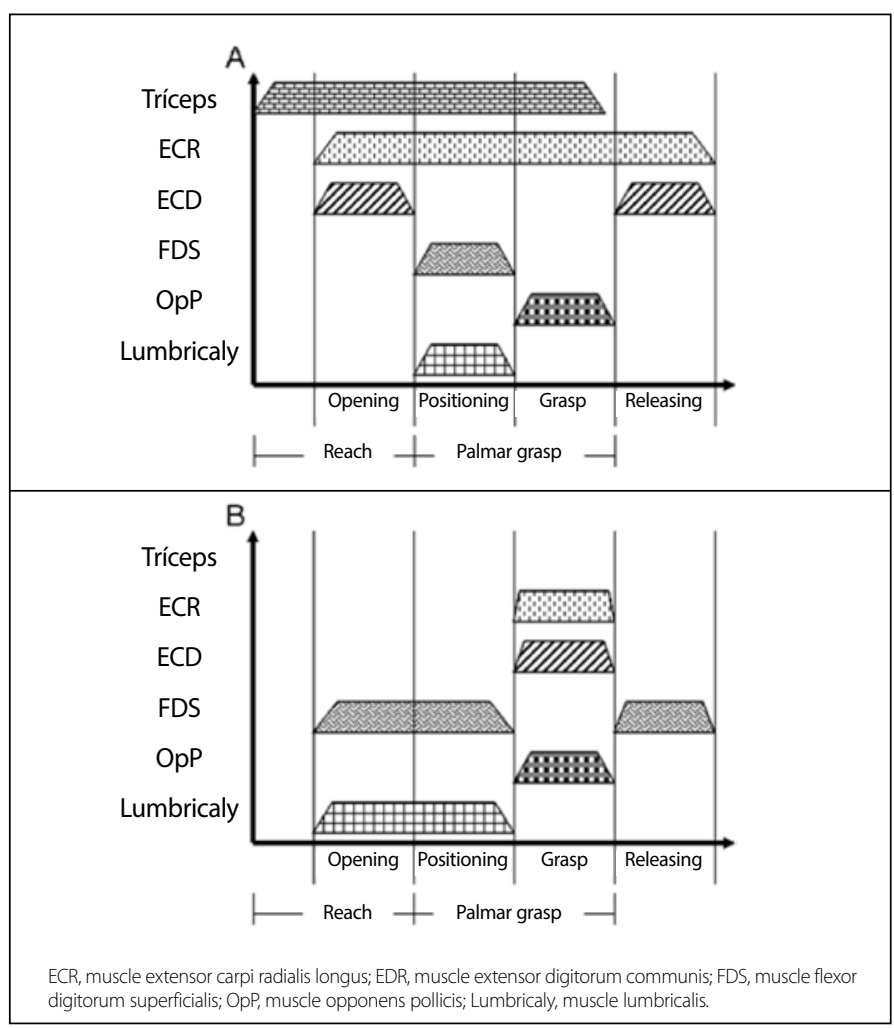

Figure 2. Schematic representation of the muscle contraction sequences used in the range of motion and palmar grasp: (A) for patients "1", "3" and "4", and (B) for patient "2". 


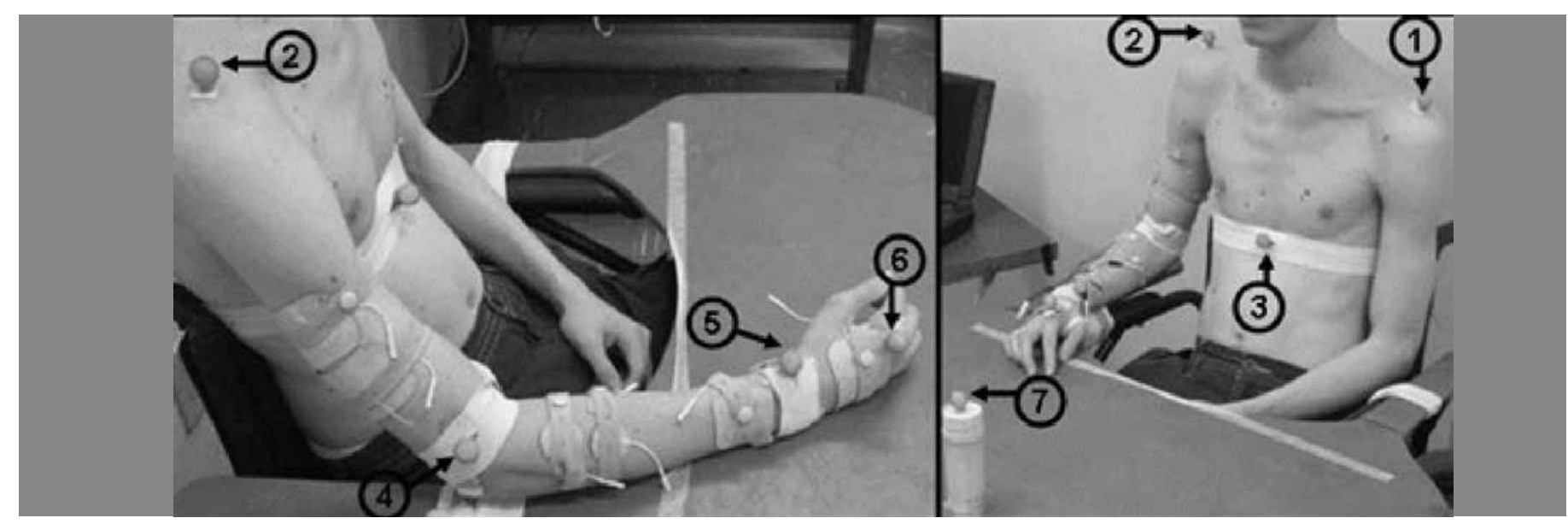

Figure 3. Markers and target positions in the horizontal (XY) and sagittal (YZ) planes. Left and right acromion (1 and 2), xiphoid process (3), lateral humeral epicondyle (4), wrist radial styloid process (5), metacarpal joint of the second finger (6) and cylinder (7). The cylinder position is in front of the patient.

(left) was left resting over the abdomen, in an attempt to minimize the influence of the non-evaluated member on postural control.

For the initial position, the dominant arm was held at the side of the trunk, with the elbow flexed at $90^{\circ}$ and the forearm in neutral position on the table. Quadriplegics subjects were seated in front of a task-table with the cylinder on it. They were instructed to reach and grasp three different cylinders (object $A: 0.200 \mathrm{~kg}$ weight, $11.5 \mathrm{~cm}$ height, $4.0 \mathrm{~cm}$ diameter; object B: $0.270 \mathrm{~kg}$ weight, $11.5 \mathrm{~cm}$ height and $5.0 \mathrm{~cm}$ diameter; and object C: $0.480 \mathrm{~kg}$ weight, $11.5 \mathrm{~cm}$ height and $6.0 \mathrm{~cm}$ diameter), one by one bringing it to the initial hand position (Figure 4).

The analysis of kinematic data was performed from the beginning of the movement (starting position), until the early return of hand position (with or without the cylinder). The cylinder was positioned in front of the subject's sternum bone, with a distance equal to the length of their arm (from the medial border of axilla to the distal wrist crease) (Figure 3).

The subjects were asked to perform five repetitions of each task with all three cylinders, in a total of 15 repetitions assisted and 15 not assisted by NMES. Once the experiment started, the subject could not touch the table with the forearm, until the task was finished. The command used to start the experiment was " $\mathrm{GO}$ ", and they were instructed to perform the movement naturally and not to worry about the velocity and time of duration. Patients were evaluated in the two situations (with and without NMES) with stimulation electrodes placed on the skin surface and the cables connected to the stimulator.

Clinical evaluation, neurological and motor levels were determined using the International Standards for Neurological and Functional Classification of Spinal Cord Injuries of American Spinal Injury Association (ASIA) ${ }^{9}$. The Functional Independence Measure (FIM) was selected to determine the functional independence level of quadriplegics. This scale consists of 18 items organized into six categories: four motor (self-care, sphincter control,

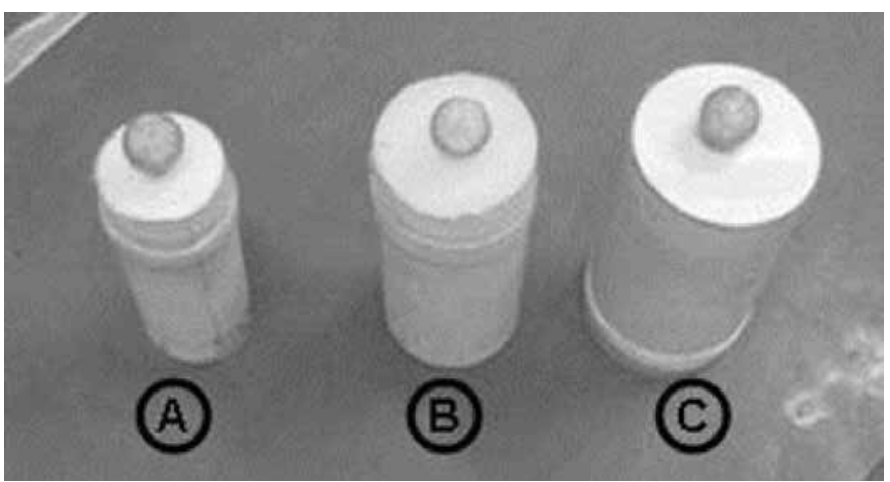

Figure 4. The three cylindrical objects. mobility, and transfer and locomotion) and two cognitive (communication and social cognition). In the FIM, patients are evaluated in each item with a seven-point scale, ranging from complete dependence to complete independence. The total lowest and highest possible scores are 18 and 126 and in the motor domain are 13 and 91, respectively ${ }^{10}$.

In order, to analyze the motor strategies for reach and grasp of different weight objects, it was performed a kinematic assessment of UL movements. Data were recorded at $240 \mathrm{~Hz}$ by four cameras with a motion capture system (Qualisys - 2.57 Sweden), after being digitally low-pass filtered at $6 \mathrm{~Hz}$ (finite impulse response) using MATLAB software.

Seven reflexive markers were positioned ( 0.015 meters of diameter) on the left and right acromion (1 and 2), xiphoid process (3), lateral humeral epicondyle (4), wrist radial styloid process (5), metacarpal joint of the second finger (6) and cylinder (7) (Figure 3).

The following kinematic variables of the arm were studied: shoulder, elbow and wrist angles; percentage of time to peak velocity; movement time; peak velocity and movement smoothness (number of velocity peaks and index of curvature). Movement variables, such as shoulder and elbow angles were calculated according to Cacho et al. ${ }^{11}$. The wrist flexion/extension in the horizontal plane were measured from markers 4 to 5 and from 5 to $6^{12}$. Wrist neutral position was considered at $0^{\circ}$ in the neutral forearm position.

The maximal peak velocity of the reach and palmar grasp was computed from the velocity vector expressed by a numerical difference of radial styloid process and xiphoid process markers in the 3-dimensional plane (XYZ). Movements onset and offsets were defined as the time at which the velocity raised above $5 \%$ and decreased below $5 \%$ of the maximal peak velocity; the percentage of the time elapsed until the maximal peak velocity was also measured (percentage of time to peak velocity) ${ }^{6}$.

The Index of curvature (reach path ratio) shows the straightness of the wrist trajectory from the initial position to the goal ${ }^{12}$. The threshold for identifying peaks in hand velocity was set at $5 \%$ of the maximum hand peak velocity, thus yielding the overall number of peaks.

To describe the sample's characteristics, according to this study variables, descriptive statistics of the continuous variables (shoulder, elbow and wrist angles, movement time, maximums peak velocity and movement smoothness) were calculated, with their mean and standard deviations values, respectively.

\section{RESULTS}

The patients were able to reach and grab all cylinders using both stimulation sequences assisted by Neuromuscular Electrical Stimulation (NMES). However, the effect was not the same without the assistance 
of NMES. The patient 4 could not get the cylinder $C$, and the others presented high difficulty to hold it due to the cylinder's weight.

The extension of the shoulder and elbow remained constant with or without the NMES (Table 2), unlike the range of motion of the wrist, which presented difference between both situations (Table 3).

The results showed that the quadriplegics produced lower peak velocity when they were assisted by the NMES. However, the reach and palmar grasp movement assisted by NMES was produced in a shorter time, while maintaining the reduction in the movement segmentation towards objects B and C, as seen in Figure 5.

\section{DISCUSSION}

The Neuromuscular Electrical Stimulation (NMES) proved to be an important tool for the UL rehabilitation in quadriplegics, providing better reach and palmar grasp movements of objects with different weights. This process might be responsible for facilitating the learning of appropriate movement patterns.

The electric stimulation of the triceps brachii did not produce any change in the range of motion of the shoulder and elbow during the reaching of the targets. This could be attributed to the ability of these subjects to be able to produce movement strategies to compensate the loss of muscle

Table 2. Shoulder and elbow angles in the sagittal plan of reach and palmar grasp movements with and without NMES.

\begin{tabular}{c|c|c|c|c}
\hline \multicolumn{2}{c|}{$\begin{array}{c}\text { Reach and palmar grasp } \\
\text { Mean/SD }\end{array}$} & Object A & Object B & Object C \\
\cline { 2 - 5 } & Mean/SD & Mean/SD & Mean/SD \\
\hline \multirow{2}{*}{$\begin{array}{c}\text { Shoulder angles in } \\
\text { sagittal plan ( }\end{array}$} & without NMES & $46.7 / 4.7$ & $46.0 / 6.2$ & $53.2 / 6.0$ \\
\cline { 2 - 5 } & with NMES & $48.7 / 4.9$ & $51.2 / 2.8$ & $52.2 / 4.5$ \\
\hline \multirow{2}{*}{$\begin{array}{c}\text { Elbow angles in } \\
\text { sagittal plan (०) }\end{array}$} & without NMES & $60.2 / 20.9$ & $64.5 / 14.4$ & $66.0 / 19.1$ \\
\cline { 2 - 5 } & with NMES & $64.0 / 21.4$ & $58.2 / 16.3$ & $64.2 / 14.7$ \\
\hline
\end{tabular}

NMES: Neuromuscular Electrical Stimulation; sd: Standard Deviation.

Table 3. Wrist angles in the horizontal plan during reach and palmar grasp movements with and without NMES.

\begin{tabular}{c|c|c|c|c}
\hline \multicolumn{2}{c}{$\begin{array}{c}\text { Reach and palmar } \\
\text { grasp Patients } \\
\text { Mean/SD }\end{array}$} & Object A & Object B & Object C \\
\cline { 3 - 5 } \multicolumn{1}{c}{1} & Mean/SD & Mean/SD & Mean/SD \\
\hline \multirow{2}{*}{2} & without NMES & $36.7 / 3.0$ & $61.8 / 11.4$ & $70.4 / 4.4$ \\
\cline { 2 - 5 } & with NMES & $59.3 / 7.8$ & $59.0 / 2.2$ & $54.8 / 2.2$ \\
\hline \multirow{2}{*}{2} & without NMES & $62.7 / 11.4$ & $66.6 / 6.8$ & $75.7 / 3.3$ \\
\cline { 2 - 5 } & with NMES & $74.5 / 3.8$ & $80.5 / 0.3$ & $86.5 / 4.3$ \\
\hline \multirow{2}{*}{3} & without NMES & $93.9 / 16.6$ & $53.55 / 12.9$ & $71.6 / 5.1$ \\
\cline { 2 - 5 } & with NMES & $33.9 / 0.62$ & $39.7 / 4.9$ & $52.2 / 9.1$ \\
\hline \multirow{2}{*}{4} & without NMES & $32.0 / 3.83$ & $30.9 / 9.7$ & $34.6 / 2.8$ \\
\cline { 2 - 5 } & with NMES & $49.5 / 6.2$ & $51.1 / 5.0$ & $48.1 / 3.4$ \\
\hline
\end{tabular}

NMES, Neuromuscular Electrical Stimulation; sd, Standard Deviation. activity of elbow extensor. However, in the absence of electric stimulation, the maximum peak velocity was higher, possibly due to the need of producing an elevated proximal joint torque for the shoulder extension ${ }^{13,14}$. In addition, it should be noted that only patient "2" did not use NMES in the triceps muscle to perform the movement (B sequence of NMES).

In Table 3, it was observed that patients" "1"and "3" (C6 motor level) showed an adjustment in the range of motion of the wrist, especially during extension (Figure 6), with reduced wrist flexion, resulting from the strategy of tenodesis performed without NMES. On the other hand, patient "4" (C5 motor level), which also used the first NMES sequence, showed an improvement in wrist extension, which was helpful for the opening and palmar grasp of cylinder C. This same movement could not be performed without NMES. Finally, patient "2" (C7 motor level), who used the second sequence of NMES, presented an increase in the wrist amplitude, which was expected because this sequence had the objective of increasing the flexor phase, in order to contribute with

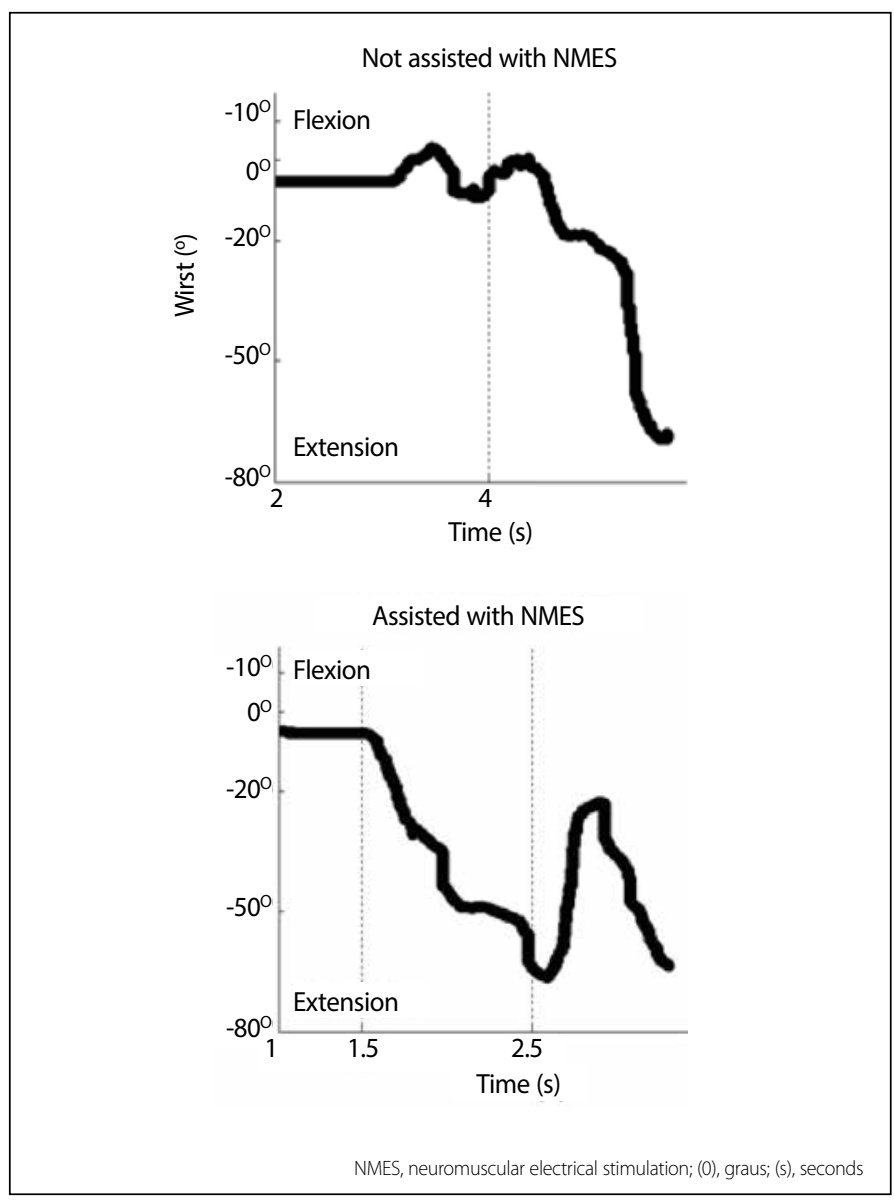

Figure 6. Wrist range of motion of patient 1 (during reach-and-grasp cylinder B).

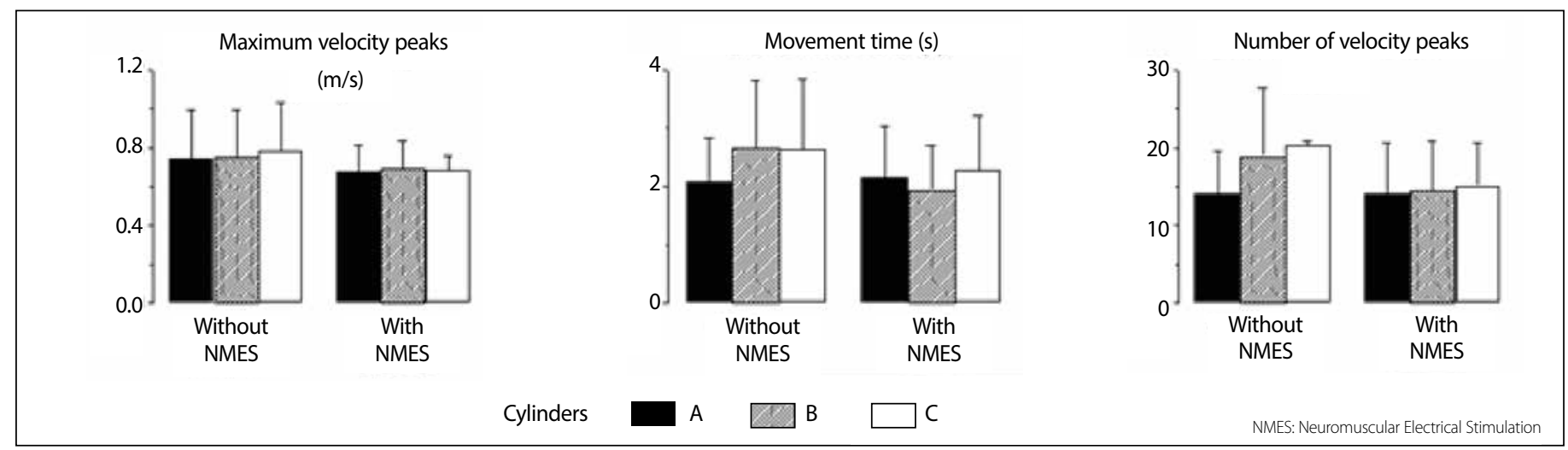

Figure 5. Maximum velocity peak, movement time, and number of velocity peaks during reach and palmar grasp movements with or without NMES. 
the wrist flexion and fingers extension at the moment of opening hand and also with the wrist extension and fingers flexion during palmar grasp phase?.

The reduction in the movement time assisted by NMES may be due to the standard parallel used during the movements. Oppositely, the pattern without NMES was performed in series, i.e. first occurs the reaching movement followed by a hand opening and grasp in the position phase. In the parallel pattern, as shown in the NMES sequence, the opening and positioning occur during the reach phase.

The greater number of velocity peaks observed during movements without NMES towards cylinders B and C was possibly due to the difficulty of adjusting the hand opening and prehension strength. However, this difficulty is also presented with NMES assistance, although the use of stimulation might facilitate this process. Regarding the interface of the stimulator microprocessor, all patients had some kind of difficulty at the beginning of the training, but after the adaptation period, these difficulties disappeared.

Shimada et al. ${ }^{15}$ assessed muscular grip strength with and without stimulation (implanted electrodes) and observed that assisted grasp showed greater strength than without assistance. It is also believed that the program of muscular strength in addition to the position of wrist extension, provided to quadriplegics an increase in strength of the fingers' flexor muscles during the cylinders grasp. Muscle strengthening provided by NMES is necessary after spinal cord injury due to the changes in the properties of the muscle fibers, including to avoid muscle atrophy ${ }^{16}$. Therefore, strength training offers an increase in muscle strength, which increases fatigue resistance of the muscle during the NMES application ${ }^{17}$.

The training of reach and palmar grasp assisted by NMES has demonstrated great potential and should be used as an intervention strategy to recover upper extremity function in quadriplegics. Training and use of appropriate motor patterns by NMES appears to contribute to adequate afferent and efferent information, inducing a modulation of spinal circuits, improving the performance and motor learning and favoring to enhance the cortical excitability 7,17 .

\section{CONCLUSION}

The present study shows that reaching and grasping training assisted by NMES is able to produce motor patterns more similar to healthy subjects' patterns and also to adequate patterns training at motor level of each patient. Therefore, NMES assisted therapy could be used as an add-on in functional motor retraining of UL of quadriplegics. The present study also demonstrates a measurement method that along with traditional clinical instruments might offer quantitative information, which evaluates therapeutic techniques.

\section{ACKNOWLEDGMENT}

The State of São Paulo Foundation for Research - FAPESP (\#06/58891-4).

All authors declare no potential conflict of interest related to this article.

AUTHORS' CONTRIBUTIONS: Each author (EWAC (0000-0001-9142-1940)*, ACJ (0000-0002-9893-5204)*, ROC (0000-0002-0440-8594)*, RLO (0000-0001-6771-4890)*, NMFVL (00000003-3432-0654)* and EMSF (0000-0002-0732-5049)*) made significant individual contributions to this manuscript. EWAC, ACJ and ROC were the main contributors in the drafting of the manuscript. EWAC and ROC monitored the patients and collected clinical data. ACJ, RLO and NMFVL assessed the data from the statistical analysis. EWAC, ACJ, ROC, RLO, NMFVL and EMSF performed the literature search, reviewed the manuscript, and contributed to the intellectual concept of the study.. *ORCID (Open Researcher and Contributor ID).

\section{REFERENCES}

1. Gregersen H, Lybek M, Johannesen IL, Leicht P, Nissen UV, Biering-Sørensen F. Satisfaction with upper extremity surgery in individuals with tetraplegia. J Spinal cord Med. 2015;38(2):161-9.

2. Martin R, Johnston K, Sadowsky C. Neuromuscular Electrical Stimulation-Assisted Grasp Training and Restoration of Function in the Tetraplegic Hand: A Case Series. Am J Occup Ther. 2012;66(4):471-7.

3. Popovic MR, Thrasher TA, Adams ME, Takes V, Zivanovic V, Tonack MI. Functional electrical therapy: retraining grasping in spinal cord injury. Spinal Cord. 2006;44(3):143-51.

4. Marino RJ, Patrick M, Albrigh W, Leiby BE, Mulcahey MJ, Schmidt-Read M, et al. Development of an Objective Test of Upper-Limb Function in Tetraplegia. Am J Phys Med Rehabil. 2012;91(6):478-86.

5. Ferreira VMV, Varoto R, Cacho EWA, Cliquet A. Relationship between function, strength and electromyography of upper extremities of persons with tetraplegia. Spinal Cord. 2012;50(1):28-32.

6. Cacho EWA, De Oliveira R, Ortolan RL, Varoto R, Cliquet A. Upper limb assessment in tetraplegia: clinical, functional and kinematic correlations. Int J Rehabil Res. 2011;34(1):65-72.

7. Mateo S, Roby-Brami A, Reilly KT, Rossetti Y, Collet C, Rode G. Upper limb kinematics after cervical spinal cord injury: a review. J Neuroeng Rehabil. 2015;12:9.

8. Murphy MA, Sunnerhagen KS, Johnels B, Willén C. Three-dimensional kinematic motion analysis of a daily activity drinking from a glass: a pilot study. J Neuroeng Rehabil. 2006;3:18.

9. Ditunno JF. Outcome measures: evolution in clinical trials of neurological/functional recovery in spinal cord injury. Spinal Cord. 2010;48(9):674-84.
10. Van Tuij JH, Janssen-Potten YJM, Seelen HAM. Evaluation of upper extremity motor function tests in tetraplegics. Spinal Cord. 2002;40(2):51-64

11. Cacho RO, Cacho EWA, Ortolan RL, Cliquet A, Borges G. Trunk Restraint Therapy: The Continuous Use of the Harness Could Promote Feedback Dependence in Post-stroke Patients. Medicine (Baltimore). 2015;94(12):e641.

12. Wagner JM, Rhodes JA, Patten C. Reproducibility and minimal detectable change of three-dimensional kinematic analysis of reaching tasks in people with hemiparesis after stroke. Phys Ther. 2008;88(5):652-63

13. Hoffmann G, Laffont I, Hanneton S, Roby-Brami A. How to extend the elbow with a weak or paralysed triceps: Control of arm kinematics for aiming in $\mathrm{C} 6 \mathrm{C} 7$ quadriplegic patients. Neuroscience. 2006;139(2):749-65.

14. Kalsi-Ryan S, Verrier MC. A synthesis of best evidence of restoration of upper-extremity function in people with tetraplegia. Physiother Can. 2011;63(4): 474-89.

15. Shimada Y, Chida S, Matsunaga T, Misawa A, Ito H, Sakuraba T, et al. Grasping Power by Means of Functional Electrical Stimulation in a Case of C6 Complete Tetraplegia. Tohoku J Exp Med. 2003;201(2):91-6.

16. Popovic DB, Sinkjaer T. Control of movement for the physiology disabled. London: Springer-Verlag; 2000

17. Lu X, Battistuzzo CR, Zoghi M, Galea MP. Effects of training on upper limb function after cervical spinal cord injury: a systematic review. Clin Rehabil. 2015;29(1):3-13. 